\title{
Enteral Hydration in High-flow Therapy for Infants with Bronchiolitis: Secondary Analysis of a Randomized Trial
}

Franz E. Babl MD ${ }^{\text {a-d }}$, Donna Franklin, MBA ${ }^{\text {a,e-i, }}$ Luregn J Schlapbach MD ${ }^{\text {e,g-i }}$, Ed Oakley MBBS $^{\mathrm{a}-\mathrm{d}}$, Stuart Dalziel PhD ${ }^{\mathrm{e}, \mathrm{j}, \mathrm{k}}$, Jennifer A. Whitty PhD ${ }^{\mathrm{l} \text {, Jocelyn Neutze MBChB }}{ }^{\mathrm{a}, \mathrm{m}, \mathrm{n}}$, Jeremy Furyk MBBS a,o,p, Simon Craig MBBS ${ }^{\text {a,q,r }}$, John F Fraser PhD ${ }^{\text {e,g }}$, Mark Jones PhD ${ }^{\text {s }}$, Andreas Schibler, MD ${ }^{\text {ef, }, \mathrm{g}, \mathrm{i}}$ on behalf of Paediatric Research in Emergency Departments International Collaborative and Pediatric Critical Care Research Group

\footnotetext{
${ }^{1 a}$ Paediatric Research in Emergency Departments International Collaborative (PREDICT), Melbourne, Victoria, Australia.

${ }^{2 b}$ Royal Children's Hospital, Melbourne, Emergency Department, Victoria, Australia.

${ }^{3 c}$ Murdoch Children's Research Institute, Melbourne, Victoria, Australia.

${ }^{4 d}$ Department of Paediatrics, Faculty of Medicine, Dentistry and Health Sciences, University of Melbourne, Melbourne, Victoria, Australia.

${ }^{5 e}$ Pediatric Critical Care Research Group, Queensland Children's Hospital and The University of Queensland, Brisbane, Australia.

${ }^{6 f}$ Mater Research Institute, The University of Queensland, Brisbane, Australia.

${ }^{7 \mathrm{~g}}$ The University of Queensland, School of Medicine, Brisbane, Australia.

${ }^{8 h}$ Critical Care Research Group, Adult Intensive Care Service, The Prince Charles Hospital, Brisbane, Australia.

${ }^{9 i}$ Department of Pediatrics, Bern University Hospital, Inselspital, University of Bern, Bern, Switzerland.

${ }^{10 j}$ Children’s Emergency Department, Starship Children’s Hospital, Auckland, New Zealand.

${ }^{11 \mathrm{k}}$ Liggins Institute, University of Auckland, Auckland, New Zealand.

${ }^{12 l}$ Health Economics Group, Norwich Medical School, University of East Anglia, Norwich UK.

${ }^{13 m}$ KidzFirst Middlemore Hospital, Auckland, New Zealand.

${ }^{14 n}$ University of Auckland, Auckland, New Zealand.

150 James Cook University, College of Medicine and Dentistry, Townsville, Queensland, Australia.

${ }^{16 p}$ Emergency Department, The Townsville Hospital, Townsville, Queensland, Australia.

${ }^{17 q}$ Department of Medicine, School of Clinical Sciences, Monash University, Clayton,

Victoria, Australia.

${ }^{18 r}$ Paediatric Emergency Department, Monash Medical Centre, Monash Health, Clayton, Victoria, Australia

${ }^{19 s}$ School of Public Health, University of Queensland.
}

\section{Correspondence to:}

Prof Franz Babl

Murdoch Children's Research Institute

The Royal Children's Hospital

59i Flemington Road nuscript accepted for publication and has undergone full peer review but Parkville, Victoria 3052 Australia
has not been though copyediting, typesetting, pagination and proofreading process, which
Email franz.babl@rch.org.au

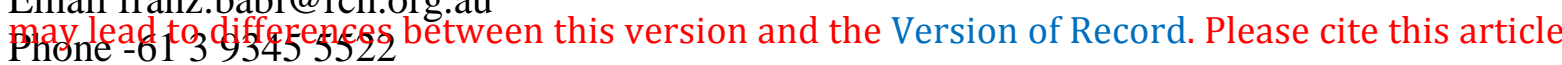
as doi: 10.1111/jpc.14799 
Short Title: Hydration in High Flow

\title{
Funding
}

The study was funded by a project grant from the National Health and Medical Research Council (NHMRC, GNT1081736), Canberra, Australia, and the Emergency Medicine Foundation, Brisbane, Australia. Regional site funding was obtained for Ipswich Hospital from the Ipswich Hospital Foundation and the Gold Coast University Hospital (GCUH) from the GCUH Foundation. Drs Schibler and Fraser received a research fellowship from the Queensland Health Department, Australia. PREDICT sites were supported by a National Health and Medical Research Council Centre of Research Excellence grant for pediatric emergency medicine (GNT1058560). Victorian sites received infrastructure support from the Victorian Government's Infrastructure Support Program, Melbourne, Australia. Dr Babl was part funded by a Royal Children's Hospital Foundation grant, a Melbourne Campus Clinician Scientist Fellowship, Melbourne, Australia and an NHMRC Practitioner Fellowship. Dr Dalziel was part funded by a grant from the Health Research Council of New Zealand (HRC), Auckland, New Zealand. The Townsville Hospital was part funded by a SERTA grant (Study, Education and Research Trust Account). The high-flow equipment and consumables for all study sites were provided free of charge by Fisher \& Paykel Healthcare (Auckland, New Zealand), who had no involvement in design, conduct, and analysis of the study.

\section{Financial disclosure}

Drs Franklin, Dalziel, Fraser and Schibler received travel support from Fisher and Paykel Healthcare. Dr Fraser reports research grant support by Fisher and Paykel Healthcare.

\section{Conflicts of interest: none}

Clinical Trial registration: The trial is registered with the Australian and New Zealand Clinical Trials Registry ACTRN12613000388718. No further data are available.

\author{
Abbreviations \\ NGT nasogastric tube \\ IV intravenous \\ RCT randomized controlled trial \\ CRF clinical report form
}

\section{Table of contents summary}

Infants with bronchiolitis on high flow for hypoxic respiratory failure can be safely hydrated enterally.

\section{What is already know}

In infants admitted with bronchiolitis not on high flow nasogastric hydration has been shown to be effective and safe. It is unclear if children receiving high-flow in bronchiolitis can be safely hydrated enterally as well.

\section{What this study adds}

We assessed the form of hydration in 505 infants who received high flow for hypoxic respiratory failure within a randomised trial. Enteral hydration was safe and the majority of infants on high flow were exclusively hydrated via nasogastric tube. 


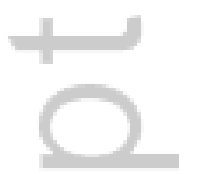

4 


\section{Contributors statement page}

Ms Franklin and Drs Babl and Schibler conceptualized and designed the study, drafted the initial manuscript and reviewed and revised it.

Drs Schlapbach, Oakley, Craig, Neutze, Furyk and Dalziel assisted with the design of the study, data collection and reviewed and revised the manuscript.

Drs Fraser, Jones and Whitty assisted with the conceptualization and design of the study, the development of study materials and reviewed and revised the manuscript.

All authors approved the final manuscript as submitted and agree to be accountable for all aspects of the work. 


\section{Enteral Hydration in High-flow Therapy for Infants with Bronchiolitis: Secondary Analysis of a Randomized Trial}

Franz E. Babl MD ${ }^{\mathrm{a}-\mathrm{d}}$, Donna Franklin, MBA ${ }^{\mathrm{a}, \mathrm{e}-\mathrm{i},}$ Luregn J Schlapbach MD ${ }^{\text {e,g-i }}$, Ed Oakley MBBS $^{\mathrm{a}-\mathrm{d}}$, Stuart Dalziel PhD ${ }^{\mathrm{e}, \mathrm{j}, \mathrm{k}}$, Jennifer A. Whitty PhD ${ }^{\mathrm{l} \text {, Jocelyn Neutze MBChB }}{ }^{\mathrm{a}, \mathrm{m}, \mathrm{n}}$, Jeremy Furyk MBBS a,o,p, Simon Craig MBBS ${ }^{\text {a,q,r }}$, John F Fraser PhD ${ }^{\text {e,g }}$, Mark Jones PhD ${ }^{\text {s }}$, Andreas Schibler, MD e,f,g,i on behalf of Paediatric Research in Emergency Departments International Collaborative and Pediatric Critical Care Research Group

\footnotetext{
${ }^{1 a}$ Paediatric Research in Emergency Departments International Collaborative (PREDICT), Melbourne, Victoria, Australia.

${ }^{2 b}$ Royal Children's Hospital, Melbourne, Emergency Department, Victoria, Australia.

${ }^{3 c}$ Murdoch Children's Research Institute, Melbourne, Victoria, Australia.

${ }^{4 d}$ Department of Paediatrics, Faculty of Medicine, Dentistry and Health Sciences, University of Melbourne, Melbourne, Victoria, Australia.

${ }^{5 e}$ Pediatric Critical Care Research Group, Queensland Children's Hospital and The University of Queensland, Brisbane, Australia.

${ }^{6 f}$ Mater Research Institute, The University of Queensland, Brisbane, Australia.

${ }^{7 \mathrm{~g}}$ The University of Queensland, School of Medicine, Brisbane, Australia.

${ }^{8 h}$ Critical Care Research Group, Adult Intensive Care Service, The Prince Charles Hospital, Brisbane, Australia.

${ }^{9 i}$ Department of Pediatrics, Bern University Hospital, Inselspital, University of Bern, Bern, Switzerland.

${ }^{10 j}$ Children’s Emergency Department, Starship Children’s Hospital, Auckland, New Zealand.

${ }^{11 \mathrm{k}}$ Liggins Institute, University of Auckland, Auckland, New Zealand.

${ }^{12 l}$ Health Economics Group, Norwich Medical School, University of East Anglia, Norwich UK.

${ }^{13 m}$ KidzFirst Middlemore Hospital, Auckland, New Zealand.

${ }^{14 n}$ University of Auckland, Auckland, New Zealand.

150 James Cook University, College of Medicine and Dentistry, Townsville, Queensland, Australia.

${ }^{16 p}$ Emergency Department, The Townsville Hospital, Townsville, Queensland, Australia.

${ }^{17 q}$ Department of Medicine, School of Clinical Sciences, Monash University, Clayton, Victoria, Australia.

${ }^{18 r}$ Paediatric Emergency Department, Monash Medical Centre, Monash Health, Clayton, Victoria, Australia

${ }^{19 s}$ School of Public Health, University of Queensland.
}

\section{Correspondence to:}

Prof Franz Babl

Murdoch Children's Research Institute 
The Royal Children's Hospital

50 Flemington Road

Parkville, Victoria 3052 Australia

Email franz.babl@rch.org.au

Phone -61 393455522

Short Title: Hydration in High Flow

\title{
Funding
}

The study was funded by a project grant from the National Health and Medical Research Council (NHMRC, GNT1081736), Canberra, Australia, and the Emergency Medicine Foundation, Brisbane, Australia. Regional site funding was obtained for Ipswich Hospital from the Ipswich Hospital Foundation and the Gold Coast University Hospital (GCUH) from the GCUH Foundation. Drs Schibler and Fraser received a research fellowship from the Queensland Health Department, Australia. PREDICT sites were supported by a National Health and Medical Research Council Centre of Research Excellence grant for pediatric emergency medicine (GNT1058560). Victorian sites received infrastructure support from the Victorian Government's Infrastructure Support Program, Melbourne, Australia. Dr Babl was part funded by a Royal Children's Hospital Foundation grant, a Melbourne Campus Clinician Scientist Fellowship, Melbourne, Australia and an NHMRC Practitioner Fellowship. Dr Dalziel was part funded by a grant from the Health Research Council of New Zealand (HRC), Auckland, New Zealand. The Townsville Hospital was part funded by a SERTA grant (Study, Education and Research Trust Account). The high-flow equipment and consumables for all study sites were provided free of charge by Fisher \& Paykel Healthcare (Auckland, New Zealand), who had no involvement in design, conduct, and analysis of the study.

\section{Financial disclosure}

Drs Franklin, Dalziel, Fraser and Schibler received travel support from Fisher and Paykel Healthcare. Dr Fraser reports research grant support by Fisher and Paykel Healthcare.

\section{Conflicts of interest: none}

Clinical Trial registration: The trial is registered with the Australian and New Zealand Clinical Trials Registry ACTRN12613000388718. No further data are available.

\author{
Abbreviations \\ NGT nasogastric tube \\ IV intravenous \\ RCT randomized controlled trial \\ CRF clinical report form
}

\section{Table of contents summary}

Infants with bronchiolitis on high flow for hypoxic respiratory failure can be safely hydrated enterally. 


\section{What is already know}

In infants admitted with bronchiolitis not on high flow nasogastric hydration has been shown to be effective and safe. It is unclear if children receiving high-flow in bronchiolitis can be safely hydrated enterally as well.

\section{What this study adds}

We assessed the form of hydration in 505 infants who received high flow for hypoxic respiratory failure within a randomised trial. Enteral hydration was safe and the majority of infants on high flow were exclusively hydrated via nasogastric tube. 


\section{Contributors statement page}

Ms Franklin and Drs Babl and Schibler conceptualized and designed the study, drafted the initial manuscript and reviewed and revised it.

Drs Schlapbach, Oakley, Craig, Neutze, Furyk and Dalziel assisted with the design of the study, data collection and reviewed and revised the manuscript.

Drs Fraser, Jones and Whitty assisted with the conceptualization and design of the study, the development of study materials and reviewed and revised the manuscript.

All authors approved the final manuscript as submitted and agree to be accountable for all aspects of the work. 


\begin{abstract}
OBJECTIVE

Nasal high-flow oxygen therapy is increasingly used in infants for supportive respiratory therapy in bronchiolitis. It is unclear whether enteral hydration is safe in children receiving high-flow.
\end{abstract}

\title{
STUDY DESIGN
}

We performed a planned secondary analysis of a multi-center, randomized controlled trial of infants aged $<12$ months with bronchiolitis and an oxygen requirement. Children were assigned to treatment with either high-flow or standard-oxygen therapy with optional rescue high-flow. We assessed adverse events based on how children on high-flow were hydrated: intravenously (IV), via bolus or continuous nasogastric tube (NGT) or orally.

\section{RESULTS}

505 patients on high-flow via primary study assignment $(n=408)$, primary treatment $(n=10)$ or as rescue therapy ( $n=87)$ were assessed. While on high flow 15 of 505 (3.0\%) received only IV fluids on high-flow, 360 (71.3\%) received only enteral fluids and 93 (18.4\%) received both IV and enteral fluids. The route was unknown in 37 (7.3\%). Of the 453 high-flow infants hydrated enterally patients could receive one or more methods of hydration. 80 (15.8\%) received NGT bolus, 217 (43.0\%) NGT continuous, 118 (23.4\%) both bolus and continuous, 32 (6.3\%) received only oral hydration and 171 (33.9\%) a mix of NGT and oral hydration.

None of the patients receiving oral or NGT hydration on high-flow sustained pulmonary aspiration (0\%; 95\% CI N/A); one patient had a pneumothorax (0.2\%; 95\% CI 0.0 to $0.7 \%)$. 


\section{CONCLUSIONS}

The vast majority of children with hypoxic respiratory failure in bronchiolitis can be safely hydrated enterally during the period when they receive high-flow.

\section{What is already know}

In infants admitted with bronchiolitis not on high flow nasogastric hydration has been shown to be effective and safe. It is unclear if children receiving high-flow in bronchiolitis can be safely hydrated enterally as well.

\section{What this study adds}

We assessed the form of hydration in 505 infants who received high flow for hypoxic respiratory failure within a randomised trial. Enteral hydration was safe and the majority of infants on high flow were exclusively hydrated via nasogastric tube. 


\section{INTRODUCTION}

Bronchiolitis, an acute lower airway lung disease is the most common reason for non-elective hospital admission in infants. No interventions have shown efficacy ${ }^{1,2}$ and American Academy of Pediatrics and Australasian Bronchiolitis guidelines recommend only supportive therapy including oxygen therapy for hypoxia, respiratory support and the maintenance of hydration. 3,4

Three methods of hydration and feeding are available for infants diagnosed with bronchiolitis including intravenous (IV), enteral hydration via nasogastric tube (NGT) or oral hydration. Enteral hydration has several theoretical advantages such as physiological benefits and allowing the additional administration of calories. In infants not requiring respiratory support, IV and NGT hydration have been shown to be equally efficacious and safe in bronchiolitis infants. ${ }^{5,6}$ Oral hydration remains controversial particularly in infants with more severe disease with either inadequate intake or risk of aspiration.

Nasal high-flow oxygen therapy has emerged as a means to provide respiratory support in bronchiolitis. ${ }^{7-12}$ We have recently conducted a multi-center randomized controlled trial (RCT) which demonstrated that high-flow oxygen therapy can be provided safely in ward settings with a lower risk of treatment failure than standard oxygen therapy but no difference in hospital length of stay or duration of oxygen therapy. ${ }^{13}$ It is unclear, however, if enteral hydration via 
NGT or orally can be safely administered in infants on high-flow oxygen therapy. In a secondary analysis of the RCT we set out to assess if infants on high-flow oxygen therapy can safely receive enteral hydration.

\section{METHODS}

\section{STUDY DESIGN}

The parent study was an unblinded RCT comparing high-flow oxygen therapy with standardoxygen therapy in emergency departments and general pediatric inpatient units in 17 tertiary and regional hospitals in Australia and New Zealand between October 2013 and August 2016. ${ }^{13}$ The human research ethics committee at each participating site approved the study. The study protocol has been published. ${ }^{14}$ The study protocol was registered with the Australian and New Zealand Clinical Trials Registry (ACTRN12613000388718).

\section{PATIENTS}

Infants less than 12 months of age were eligible for inclusion upon presentation to emergency or pediatric inpatient units with clinical signs of bronchiolitis and an oxygen requirement. Bronchiolitis was defined according to the American Academy of Pediatrics ${ }^{3}$ criteria as an infant with symptoms of respiratory distress associated with symptoms of a viral respiratory tract infection. ${ }^{2}$ We excluded critically ill infants with immediate need for respiratory support and intensive care admission, infants with cyanotic heart disease, apneas, basal skull fracture, 
upper airway obstruction, craniofacial malformations and infants receiving home oxygen therapy. Written informed consent was obtained from all parents or guardians.

\section{STUDY INTERVENTION}

High-flow group infants received heated and humidified high-flow oxygen therapy at a rate of $2 \mathrm{~L} / \mathrm{kg}$ per minute delivered via the Optiflow ${ }^{\mathrm{TM}}$ system (Fisher \& Paykel Healthcare; Auckland, New Zealand) using an age-appropriate Optiflow Junior ${ }^{\mathrm{TM}}$ cannula and the Airvo $2^{\mathrm{TM}}$ high-flow device. The standard-oxygen group infants were placed on subnasal oxygen via nasal cannula up to a maximum of $2 \mathrm{~L} / \mathrm{min}$. Details of the study protocol are available in a separate publication. ${ }^{14}$

For all infants who received high-flow a NGT placement was recommended for venting of the stomach at least 4 hourly to avoid gastric hyperextension. IV placement was not mandated or encouraged. Depending on the clinician's preference oral intake was allowed if tolerated, particularly during weaning of the treatment. Nursing care management was to continue NGT feeding during high-flow delivery and to stop high-flow and change to lowflow humidified oxygen via the same high-flow Airvo2 device during oral feeding. In this case the infant would remain undisturbed with the same nasal cannula for this time period and up to a maximum of 20 minutes before ceasing oral hydration and returning to previous high-flow settings via the Airvo2 device. Type of hydration during high-flow and low-flow humidified oxygen was recorded. Information as to whether or not the flow rate was turned down during enteral hydration was turned down was not collected. Data on type of hydration 
during high-flow and low-flow humidified oxygen was obtained where accurately recorded in the medical charts. This was at times difficult to adhere to and collect data on, as parents may have fed their infant when the nurse was not present.

\section{STUDY OUTCOMES}

The primary outcome of the parent study was treatment failure resulting in escalation of care during the current hospital admission. At the point of care the treating clinicians determined the presence of treatment failure if at least three of four clinical criteria were met and escalation of care was required. ${ }^{13}$ The clinicians were allowed to escalate therapy if they were concerned for other clinical reasons not captured in the four clinical criteria. For children in the standard-oxygen group who received escalation of care, it was suggested to use rescue high-flow in the inpatient ward environment.

For this study we assessed all infants who received high-flow oxygen therapy either as their primary commencement therapy regardless of randomized study assignment or as rescue high-flow therapy if they failed standard-oxygen therapy. Detailed hydration data were collected and included in the CRF from November 2015. Primary analysis of this study was adverse events based on how children on high-flow were hydrated, either via IV route, via bolus or continuous NGT or orally. We collected adverse events by specifically asking for certain adverse events. A serious adverse event was defined as any event that was fatal, lifethreatening, permanently disabling, incapacitating or resulted in a prolonged hospital stay. 


\section{STATISTICAL ANALYSIS}

Descriptive statistics were used to report on the baseline characteristics of the infants who received high-flow and their means of hydration with 95\% confidence intervals for key proportions.

\section{RESULTS}

\section{PATIENT CHARACTERISTICS}

Of 1,638 infants randomized 166 parents/guardians (10\%) declined consent to use data, thus 1,472 infants were included in the analyses of the parent study. Of these, 739 were primarily randomized to the high-flow group and of whom 728 actually received high-flow, and 733 were primarily randomized to the standard-oxygen group and of whom 18 actually received high-flow in the first instance and 162 received rescue high-flow for a total of 908 receiving high-flow (Figure 1).

Prospective hydration data were collected for 505 patients who received high-flow and represent the study cohort analyzed. Demographic and basic clinical characteristics are shown in Table 1. The average age of the infants was 5.8 months and 217 of 393 tested (55.2\%) were RSV positive. A history of prematurity or previous hospital admission was 92 (18.2\%) and 122 (24.2\%) respectively. The mean peripheral oxygen saturation level on room air at enrolment was $88 \%$. 


\section{HYDRATION ON HIGH FLOW}

While on high-flow 15 of 505 (3.0\%) received only IV fluids, 360 (71.3\%) received only enteral feeds and 93 (18.4\%) received both IV and enteral feeds (Figure 1). For 37 (7.3\%) route of fluid administration was unknown. Of the 453 who had at least at some point been enterally fed while on high-flow 80 (15.8\%) received NGT bolus, 217 (43.0\%) NGT continuous, 118 (23.4\%) both bolus and continuous, 32 (6.3\%) received only oral feeds without NGT hydration and 171 (33.9\%) received a mix of NGT and oral feeds (Table 2). Infants less than 3 months of age had higher IV rates than older infants.

\section{ADVERSE EVENTS}

None of the patients receiving oral or NGT feeding on high flow sustained pulmonary aspiration (0\%; 95\% CI N/A); 1 patient had a pneumothorax (0.2\%; 95\% CI 0.0 to $0.7 \%)$ which was unrelated to NGT insertion and did not require a chest tube. Of note in the parent study there was one pneumothorax noted in the standard oxygen group. No life-threatening serious adverse-events were observed, specifically no emergency intubation or cardiac arrest (Table 2).

\section{DISCUSSION}

In this secondary analysis of a multi-center randomized controlled trial in infants with bronchiolitis and hypoxemia we found that the vast majority of patients $-71.3 \%$ - were solely 
fed and hydrated enterally during high-flow administration and that IV hydration was infrequently used. Most enteral hydration was via an NGT. None of the enterally fed children had a clinical aspiration or other adverse events attributable to enteral hydration.

There are several reasons why NGT feeding was used at a high rate in this study. In the first instance NGT insertion was recommended by the protocol to allow intermittent venting of the stomach. Furthermore, in Australia and New Zealand NGT hydration is used for a variety of conditions in preference to IV fluids, including in bronchiolitis and gastroenteritis, 5, 6, 15,16,17 and it became obvious very quickly in this study that enteral feeding could be safely conducted during high-flow delivery. A further advantage of hydration via NGT is that fewer attempts are needed in infants with bronchiolitis to achieve successful placement compared to IV insertion. ${ }^{5}$ A concern in NGT placement in children in contrast to adults ${ }^{18,19}$ is that there is no demonstrated means of reducing the pain and distress associated with NGT insertion. ${ }^{20}$ Anecdotally, after insertion infants fed via a NGT seem less irritable than IV hydrated infants, without the caloric content provided by formula, though there are no data to support this.

Our study has some limitations. As set out in methods we started collecting feeding data only once a section of the patients had already been enrolled in the trial when the study team realized that these data would be important secondary information. While for the majority of infants only one type of hydration was provided, for some children multiple modalities were used, and sometimes alternating modalities occurred. In addition, we did not record how long 
different modalities were used in children who had received more than one modality. In this group of infants it was difficult to determine the predominant feeding modality during highflow. The protocol recommended to decrease flow rates for feeds; this was proscribed as a safety measure when no data on high flow and feeding were available prior to this study. We did not collect why clinicians chose one modality over another nor if they adhered to the study protocol in terms of reducing high-flow during NGT bolus feeds or oral feeds. We cannot comment specifically on advantages/disadvantages of bolus versus continuous feedsneither was associated with adverse events. We did not collect details of the type of enterally used fluids.

In conclusion, we aimed to investigate how infants managed on high-flow therapy are hydrated and if enteral feeding, and NGT feeding in particular, is safe during high-flow therapy support. Our data indicates that the vast majority of children with hypoxic respiratory failure in bronchiolitis can be safely fed enterally during the period when they receive highflow. 


\section{REFERENCES}

1. Fernandes RM, Hartling L. Glucocorticoids for acute viral bronchiolitis in infants and young children. JAMA 2014;311:87-8.

2. Zorc JJ, Hall CB. Bronchiolitis: recent evidence on diagnosis and management. Pediatrics 2010;125:342-9.

3. Ralston SL, Lieberthal AS, Meissner HC, et al. Clinical Practice Guideline: The Diagnosis, Management, and Prevention of Bronchiolitis. Pediatrics. 2014;134(5):e1474-e1502 Pediatrics. 2015 Oct;136(4):782.

4. O’Brien S, Borland ML, Cotterell E, et al. Australasian bronchiolitis guideline. J Paediatr Child Health. 2018 July 15. doi 10.1111/jpc.14104.

5. Oakley E, Borland M, Neutze J, et al. Nasogastric hydration versus intravenous hydration for infants with bronchiolitis: a randomised trial. Lancet Respir Med. 2013 Apr;1(2):113-20. doi: 10.1016/S2213-2600(12)70053-X. Epub 2012 Dec 21.

6. Oakley E, Bata S, Rengasamy S, et al. Nasogastric Hydration in Infants With Bronchiolitis Less Than 2 Months of Age. J Pediatr. 2016 Nov;178:241-245.e1. doi: 10.1016/j.jpeds.2016.07.012. Epub 2016 Aug 10.

7. Manley BJ, Owen LS, Doyle LW, et al. High-flow nasal cannulae in very preterm infants after extubation. N Engl J Med 2013;369:1425-33. 
8. Lee JH, Rehder KJ, Williford L, Cheifetz IM, Turner DA. Use of high flow nasal cannula in critically ill infants, children, and adults: a critical review of the literature. Intensive Care Med 2013;39:247-57.

9. Frat JP, Thille AW, Mercat A, et al. High-Flow Oxygen through Nasal Cannula in Acute Hypoxemic Respiratory Failure. N Engl J Med 2015.

10. Mayfield S, Bogossian F, O'Malley L, Schibler A. High-Flow nasal cannula oxygen therapy for infants with bronchiolitis: Pilot study. J Paediatr Child Health in print $2014 ; 50$.

11. Bressan S, Balzani M, Krauss B, Pettenazzo A, Zanconato S, Baraldi E. High-flow nasal cannula oxygen for bronchiolitis in a pediatric ward: a pilot study. Eur J Pediatr 2013;172:1649-56.

12. Kepreotes E, Whitehead B, Attia J, et al. High-flow warm humidified oxygen versus standard low-flow nasal cannula oxygen for moderate bronchiolitis (HFWHO RCT): an open, phase 4, randomised controlled trial. Lancet 2017;389:930-9.

This article is protected by copyright. All rights reserved. 
13. Franklin D, Babl FE, Schlapbach L, et al. A.High-Flow for Infants with Bronchiolitis: A Randomized Controlled Trial. A pediatric acute respiratory intervention study (PARIS) from PREDICT and PCCRG. N Engl J Med. 2018 Mar 22;378(12):11211131. doi: 10.1056/NEJMoa1714855.

14. Franklin D, Dalziel S, Schlapbach LJ, et al. Early high flow nasal cannula therapy in bronchiolitis, a prospective randomised control trial (protocol): A Paediatric Acute Respiratory Intervention Study (PARIS). BMC Pediatr 2015;15:183.

15. Stock A, Gilbertson H. Babl FE. Confirming nasogastric tube position in the emergency department: pH testing is reliable. Ped Emerg Care 2008;24:805-9.

16. Babl F, Sherrif N, Neutze J, Borland M, Oakley E. Bronchiolitis management in pediatric emergency departments in Australia and New Zealand: a PREDICT Study. Pediatr Emerg Care. 2008; 24(10):656-658

17. Fonseca B, Holdgate A, Craig J. Enteral vs intravenous rehydration therapy for children with gastroenteritis: a metaanalysis of randomized controlled trials. Arch Pediatr Adolesc Med. 2004;158(5):483-490

18. Spektor M, Kaplan J, Kelley J, Wheary J, Dalsey W. Nebulized or sprayed lidocaine as anesthesia for nasogastric intubations. Acad Emerg Med. 2000;7(4):406-408

19. Cullen L, Taylor D, Taylor S, Chu K. Nebulized lidocaine decreases the discomfort of nasogastric tube insertion: a randomized, double-blind trial. Ann Emerg Med. 2004;44(2):131-137 
20. Babl FE, Goldfinch C, Mandrawa C, Crellin D, O'Sullivan R, Donath S.

Does nebulized lidocaine reduce the pain and distress of nasogastric tube insertion in young children? A randomized, double-blind, placebo-controlled trial.

Pediatrics 2009;123:1548-1555.

This article is protected by copyright. All rights reserved. 


\section{LEGENDS}

Figure 1.

Numbers of Infants Who Received High Flow Oxygen via Nasal Cannula and Had Hydration Status Assessed.

This article is protected by copyright. All rights reserved. 


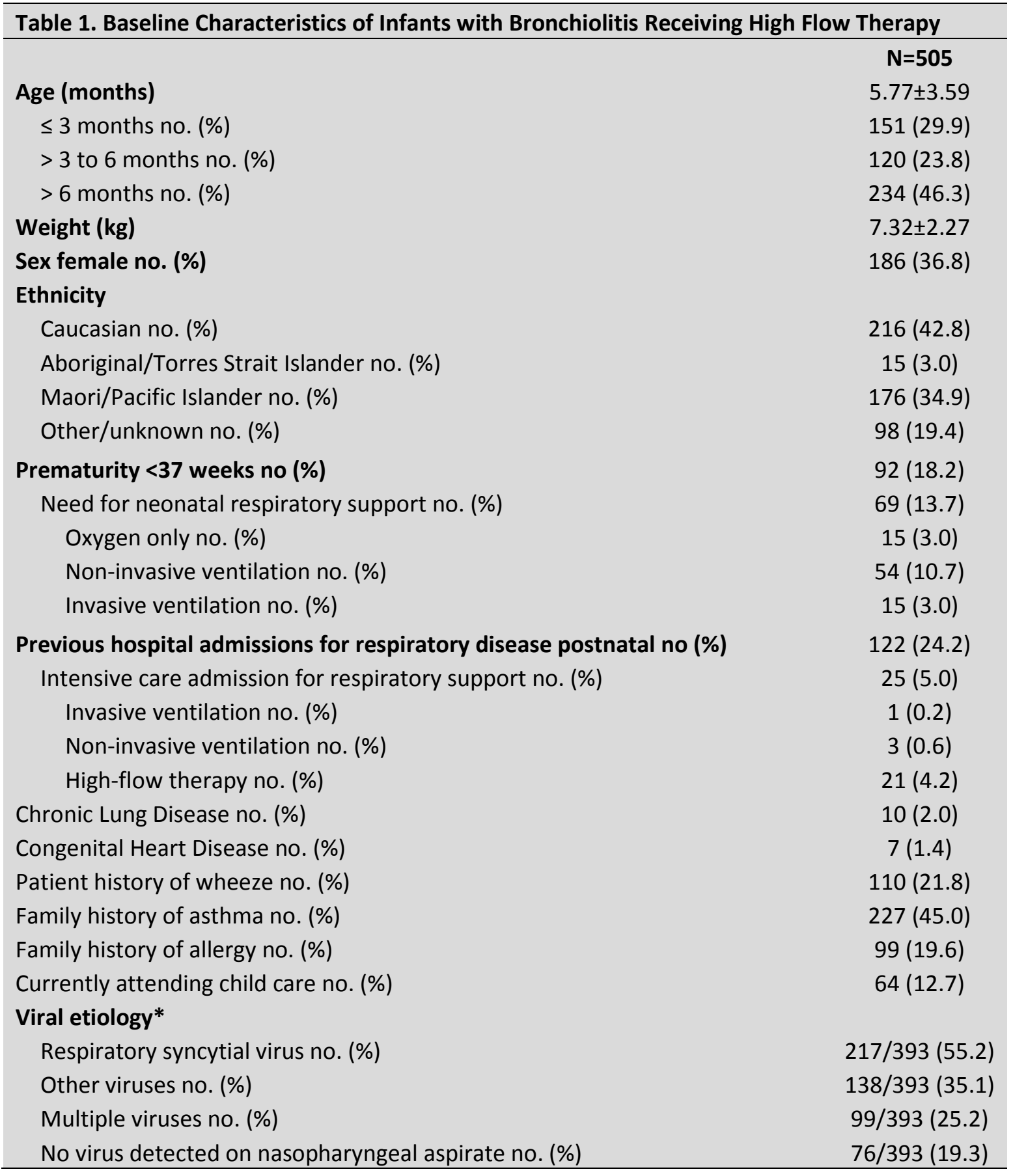

Plus-minus value denotes means and $\pm \mathrm{SD}$, medium interquartile range (IQR). *Viral testing was not mandated with lower number of tests overall obtained.

${ }^{\top}$ Multiple options possible 


\begin{tabular}{|c|c|c|c|}
\hline & $N=505$ & & \\
\hline IV fluids only & $15(3.0)$ & & \\
\hline Enteral fluids only & $360(71.3)$ & & \\
\hline NGT only & $157(31.1)$ & & \\
\hline Continuous & $83(16.4)$ & & \\
\hline Bolus & $25(5.0)$ & & \\
\hline Both continuous and bolus & $49(9.7)$ & & \\
\hline Unknown & $35(6.9)$ & & \\
\hline Oral only & $32(6.3)$ & & \\
\hline NGT and oral & $171(33.9)$ & & \\
\hline IV and enteral fluids & $93(18.4)$ & & \\
\hline Fluid administration unknown & $37(7.3)$ & & \\
\hline Enteral feeds at any time & $453(89.7)$ & & \\
\hline NGT at any time & $415(82.2)$ & & \\
\hline Continuous & $217(43.0)$ & & \\
\hline Bolus & $80(15.8)$ & & \\
\hline Both continuous and bolus & $118(23.4)$ & & \\
\hline Unknown & $38(7.5)$ & & \\
\hline Oral at any time & $248(49.1)$ & & \\
\hline Age & NGT only & IV only & Enteral at any time \\
\hline$\leq 3$ months no (\%) & $42 / 151(27.8)$ & $8 / 151(5.3)$ & $136 / 151(90.1)$ \\
\hline$>3$ to 6 months no (\%) & $34 / 120(28.3)$ & $5 / 120(4.2)$ & $106 / 120(88.3)$ \\
\hline$>6$ months no (\%) & $81 / 234(34.6)$ & $2 / 234(0.9)$ & $211 / 234(90.2)$ \\
\hline Adverse events & $N=157$ & $\mathrm{~N}=15$ & $N=453$ \\
\hline Serious adverse events no (\%) & 0 & 0 & 0 \\
\hline Pulmonary aspiration no (\%) & 0 & 0 & 0 \\
\hline Pneumothorax no (\%) & 0 & 0 & $1(0.2)$ \\
\hline Emergency intubation no (\%) & 0 & 0 & 0 \\
\hline Cardiac arrest no (\%) & 0 & 0 & 0 \\
\hline Respiratory arrest no (\%) & 0 & 0 & 0 \\
\hline Apneas no (\%) & $1(0.6)$ & $1(6.7)$ & $5(1.1)$ \\
\hline
\end{tabular}

Plus-minus values are means \pm SD. RSV denotes respiratory syncytial virus. ICU denotes intensive care unit.

"P-value for all subgroup analyses represents test of homogeneity across the odds ratios compared between subgroups 


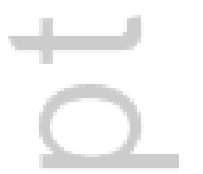

4 


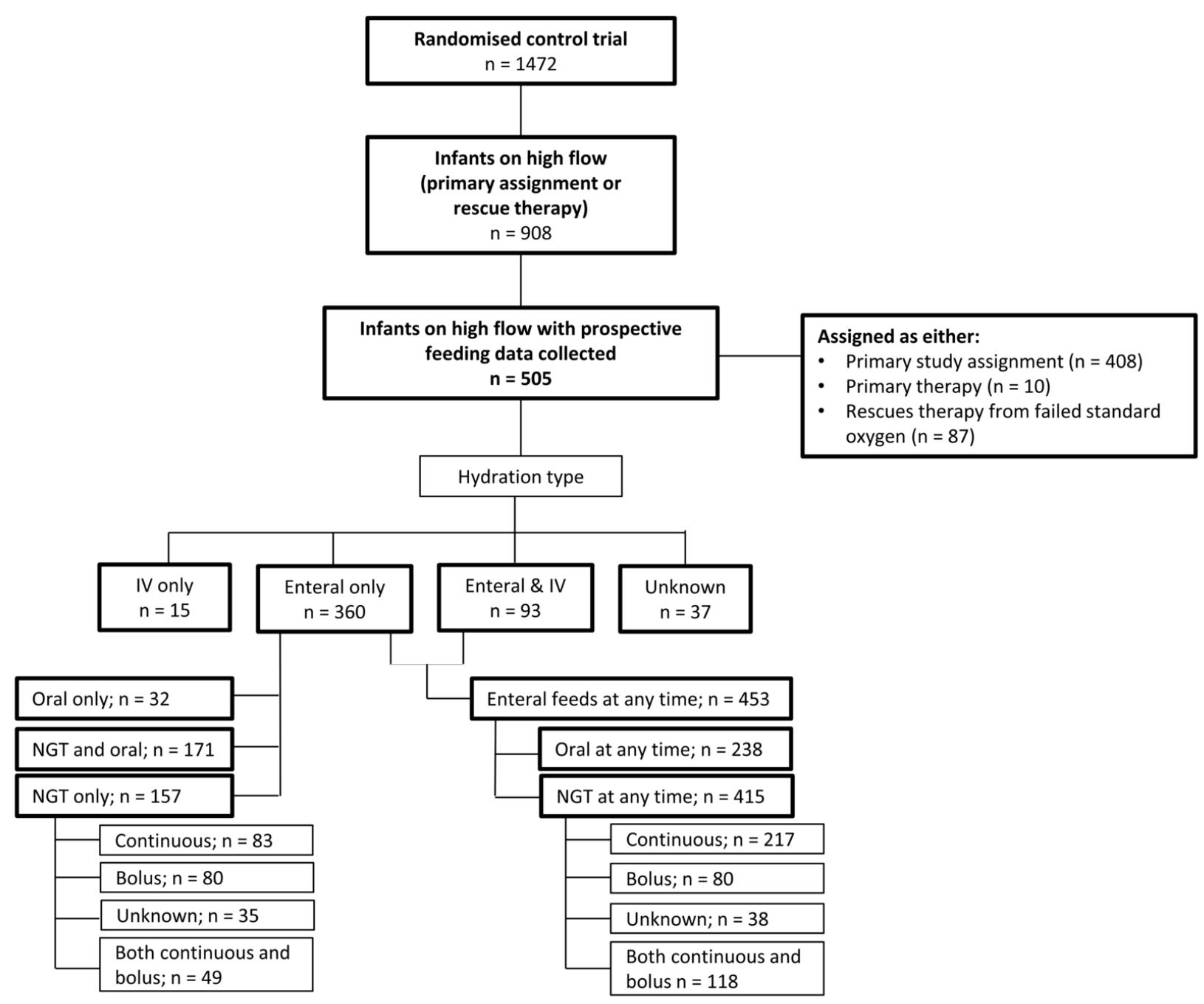

JPC_14799_Babl_patient_flowchart_15.06.19_as_submitted_removed_extra_slide..tif 


\section{University Library}

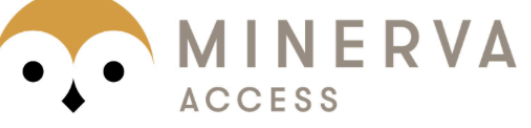

A gateway to Melbourne's research publications

Minerva Access is the Institutional Repository of The University of Melbourne

Author/s:

Babl, FE;Franklin, D;Schlapbach, LJ;Oakley, E;Dalziel, S;Whitty, JA;Neutze, J;Furyk, J;Craig, S;Fraser, JF;Jones, M;Schibler, A

Title:

Enteral hydration in high-flow therapy for infants with bronchiolitis: Secondary analysis of a randomised trial

Date:

2020-02-11

Citation:

Babl, F. E., Franklin, D., Schlapbach, L. J., Oakley, E., Dalziel, S., Whitty, J. A., Neutze, J., Furyk, J., Craig, S., Fraser, J. F., Jones, M. \& Schibler, A. (2020). Enteral hydration in high-flow therapy for infants with bronchiolitis: Secondary analysis of a randomised trial. JOURNAL OF PAEDIATRICS AND CHILD HEALTH, 56 (6), pp.950-955. https:// doi.org/10.1111/jpc.14799.

Persistent Link:

http://hdl.handle.net/11343/275389 